\title{
Predictive Factors for Conversion of Laparoscopic Cholecystectomy
}

\author{
D. C. Atmaram • K. Lakshman
}

Received: 6 February 2008 / Accepted: 19 September 2011 /Published online: 4 November 2011

(C) Association of Surgeons of India 2011

\begin{abstract}
Laparoscopic Cholecystectomy is the gold standard treatment for gallbladder diseases. However, for various reasons there is a finite chance of conversion to open cholecystectomy in some patients. To assess preoperative factors which might predict the chances of conversion and the intraoperative reason which resulted in the conversion. The SAGAR APOLLO HOSPITAL patient database was searched for patients who underwent laparoscopic cholecystectomy between July 2003 and November 2006. Sagar Apollo hospital is an urban tertiary care hospital. The records of 526 patients who underwent laparoscopic cholecystectomy were reviewed retrospectively. $14(2.6 \%)$ of the 526 patients were converted to open cholecystectomy. Preoperative Alkaline phosphatase values were raised in patients who underwent conversion and were found to be statistically significant. The most common intraoperative reason for conversion was difficulty in delineating the anatomy at the Calot's triangle. It is difficult to preoperatively predict the factors responsible for conversion.
\end{abstract}

Keywords Laparoscopic cholecystectomy · Conversion . Predictive factors

D. C. Atmaram $(\bowtie) \cdot K$. Lakshman

Sagar Apollo Hospital,

30th Cross, Tilak Nagar, Jayanagar Extension,

Bangalore 560041, India

e-mail: dratmaram@gmail.com

\section{Introduction}

Since its introduction in 1987 by Philip Mouret, laparoscopic cholecystectomy has revolutionized minimally invasive procedures and has been recognized as the gold standard treatment for gallbladder diseases [1-3]. However, for various reasons there is a finite chance of conversion to open cholecystectomy in some patients. The most common reason for conversion is the inability to correctly identify the anatomy of the Calot's triangle as a result of inflammation in the area around the gallbladder. In the present study, we have tried to assess 1) some preoperative factors that might predict the chances of conversion and 2) the intraoperative factors that resulted in the conversions.

\section{Patients and Methods}

The records of 526 patients who underwent laparoscopic cholecystectomy between July 2003 and November 2006 at the Sagar Apollo Hospital patient (an urban tertiary care hospital) were reviewed retrospectively.

A patient was considered converted, if for any reason, the planned laparoscopic procedure was abandoned and open conventional cholecystectomy was resorted to. The demographics and preoperative data of the patients who required conversion to laparotomy were studied. The factors studied were age, sex, duration of symptoms, liver function tests (LFTs), ultrasound findings and the intraoperative reason for conversion as described in the operation notes. The patients who underwent a planned open cholecystectomy were not included in the study. Of 
the patients who underwent successful laparoscopic cholecystectomy, 14 were selected by simple randomization for comparison with the converted group. The parameters between the two groups were compared and student's $t$-test was used for statistical analysis.

\section{Operative Technique}

The standard four-trocar technique was used for all laparoscopic cholecystectomies. First, a $10-\mathrm{mm}$ port was inserted in the subumbilical region under vision, followed by two 5-mm lateral ports. Dissection of the Calot's triangle was done either using a hook or a Maryland forceps. Cystic duct and artery were defined and clipped separately and divided. Gallbladder removal from the liver bed was accomplished by using monopolar electrocautery and extracted through the epigastric port. When conversion was required, either a Kocher's incision or an upper midline incision was made. Decision for conversion was based on surgeon's clinical judgment. All laparoscopic cholecystectomies were performed by experienced surgeons (who have performed more than 250 laparoscopic cholecystectomies each).

\section{Results}

A total of 526 patients underwent laparoscopic cholecystectomy. Conversion to open cholecystectomy for safe completion was necessary in 14 patients (group 1) (2.6\%). The laparoscopic procedure was successfully completed in 512 patients, among these 14 patients were selected for comparison by simple randomization (group 2), using randomization table.

Among the converted group, there were four cases of acute cholecystitis, and the rest of the cases were cases of chronic calculous cholecystitis.

Age and Sex Distribution

The average age of the patient in group 1 was 62.43 years (range 43-81) and that in group 2 was 47.8 (range 11-79).

Male:female ratio was $3: 4$ and $1: 1$ in groups 1 and 2, respectively [4-6].

\section{Liver Function Tests}

Table 1 shows that the LFTs were normal in majority of the patients in either group.

Total bilirubin level was raised in three patients in the converted group and in two patients in the unconverted group. Alkaline phosphatase level was raised in two patients in group 1 and in one patient in group 2 .

\section{Ultrasound Findings}

Table 2 shows the ultrasound findings of patients in both the groups.

The ultrasound findings of group 1 patients showed increased wall thickness and dilated common bile duct in two and presence of pericholecystic fluid in one. Most patients in group 1 had multiple calculi. In group 2, five patients had increased wall thickness, whereas four had
Table 1 LFTs of both the groups

Alk Phos alkaline phosphatase, Bili bilirubin, $L F T$ liver function test, NS not significant

\begin{tabular}{|c|c|c|c|c|c|c|}
\hline \multirow[t]{2}{*}{ Pt. No } & \multicolumn{3}{|c|}{ LFT (Group 1) } & \multicolumn{3}{|c|}{ LFT (Group 2) } \\
\hline & Direct Bili & Indirect Bili & Alk Phos & Direct Bili & Indirect Bili & Alk Phos \\
\hline 1 & & & & 0.5 & 0.1 & 130 \\
\hline 2 & & & & 0.4 & 0.1 & 72 \\
\hline 3 & & & & 0.9 & 0.3 & 154 \\
\hline 4 & 0.8 & 0.1 & 59 & 0.2 & 0.1 & 198 \\
\hline 5 & & & & 1.9 & 0.2 & 118 \\
\hline 6 & 0.2 & 0.1 & 191 & 0.3 & 0.1 & 112 \\
\hline 7 & 1.6 & 0.6 & 270 & 1 & 0.2 & 84 \\
\hline 8 & 0.8 & 0.5 & 263 & 0.8 & 0.2 & 70 \\
\hline 9 & 0.4 & 0.1 & 93 & 0.7 & 0.2 & 83 \\
\hline 10 & & & & 3.3 & 2.6 & 236 \\
\hline 11 & 0.7 & 0.1 & 63 & 1.2 & 0.3 & 85 \\
\hline 12 & 1.7 & 0.5 & 75 & 0.4 & 0.1 & 77 \\
\hline 13 & 4.7 & 3.2 & 138 & 0.8 & 0.3 & 113 \\
\hline \multirow[t]{2}{*}{14} & 1.2 & 0.2 & 83 & 1.0 & 0.9 & 109 \\
\hline & NS & NS & $P<0.001$ & NS & NS & \\
\hline
\end{tabular}


Table 2 Ultrasound findings in both groups

\begin{tabular}{|c|c|c|c|c|c|c|c|c|}
\hline \multirow[t]{2}{*}{ Pt. No. } & \multicolumn{4}{|l|}{ USG (Group 1) } & \multicolumn{4}{|l|}{ USG (Group2) } \\
\hline & Wall thickness & $\mathrm{CBD}(\mathrm{mm})$ & $\begin{array}{l}\text { Pericholecystic } \\
\text { collection }\end{array}$ & Number of calculi & Wall thickness & $\mathrm{CBD}(\mathrm{mm})$ & $\begin{array}{l}\text { Pericholecystic } \\
\text { collection }\end{array}$ & Number of calculi \\
\hline 1 & & & & & $\mathrm{~N}$ & $\mathrm{~N}$ & None & Multiple \\
\hline 2 & $\mathrm{~N}$ & $\mathrm{~N}$ & $\mathrm{~N}$ & Multiple & $\mathrm{N}$ & $\mathrm{N}$ & None & Multiple \\
\hline 3 & & & & & Inc & $\mathrm{N}$ & Present & Multiple \\
\hline 4 & $\mathrm{~N}$ & 11.9 & None & Multiple & $\mathrm{N}$ & $\mathrm{N}$ & None & Multiple \\
\hline 5 & Inc & $\mathrm{N}$ & Present & Sludge & $\mathrm{N}$ & $\mathrm{N}$ & None & Multiple \\
\hline 6 & $\mathrm{~N}$ & $\mathrm{~N}$ & None & Multiple & Inc & $\mathrm{N}$ & None & Multiple \\
\hline 7 & $\mathrm{~N}$ & $\mathrm{~N}$ & None & & Inc & $\mathrm{N}$ & Minimal & Multiple \\
\hline 8 & Inc & $8-9$ & None & Multiple & $\mathrm{N}$ & $\mathrm{N}$ & None & Multiple \\
\hline 9 & $\mathrm{~N}$ & $\mathrm{~N}$ & None & Multiple & $\mathrm{N}$ & 7 & None & Single \\
\hline 10 & & & & & Inc & $\mathrm{N}$ & None & Multiple \\
\hline 11 & $\mathrm{~N}$ & $\mathrm{~N}$ & None & Multiple & $\mathrm{N}$ & $8-9$ & None & Multiple \\
\hline 12 & $\mathrm{~N}$ & $\mathrm{~N}$ & None & Multiple & $\mathrm{N}$ & $6-7$ & None & Multiple \\
\hline 13 & & & & & $\mathrm{~N}$ & $8-9$ & Minimal & Sludge \\
\hline 14 & & & & & Inc & $\mathrm{N}$ & Present & Multiple \\
\hline
\end{tabular}

$C B D$ common bile duct, $I n c$ increased, $N$ normal, USG ultra sonography

dilated common bile duct, and pericholecystic collection was seen in four. As with group 1, majority of the patients in group 2 had multiple gallstones.

\section{Operative Findings}

The most common reason for the change was the inability to identify the anatomy of the structures at the Calot's triangle as a result of inflammation in the region (Table 3).

\section{Discussion}

Laparoscopic cholecystectomy is the gold standard for gallstone disease $[2,3]$. Several studies have shown the advantages of laparoscopic cholecystectomy over conventional open cholecystectomy like decreased postoperative pain, earlier oral intake, shorter hospital stay, early resumption of normal activity and improved cosmesis [4, 7, 8]. It is important for the surgeon to understand that conversion to laparotomy is neither a failure nor a complication, but is an attempt to ensure patient safety, and the same should be explained to the patient before surgery.

Several possible factors responsible for conversion have been studied. In particular, prediction of conversion through the analysis of preoperative factors responsible for conversion has been studied. These include age; sex; obesity; diabetes mellitus; body mass index; duration of symptoms; total leucocyte count; LFT; ultrasound; acute cholecystitis; history of biliary diseases such as jaundice, cholangitis, etc.; history of pancreatitis and preoperative endoscopic retrograde cholangiopancreatography $[5,6,9,10]$. Our study focused on some of these factors.

The need for conversion is usually due to difficulty in dissection at Calot's triangle, instrument failure or a complication [11-13]. Being able to accurately predict the chance of conversion preoperatively would be beneficial; the patient could be forewarned and the surgeon could prepare for a possible longer and more difficult procedure. Studies have shown that conversion from laparoscopic to open cholecystectomy results in a significant change in the outcome for the patient, as it has higher postoperative complications and requires longer hospital stay.
Table 3 Intraoperative reasons for conversion

\begin{tabular}{lll}
\hline S.No. & Reason for conversion & No. of cases \\
\hline 1. & Dense adhesions, difficulty in dissection of Calot's triangle & 10 \\
2. & Gallbladder embedded in the liver & 1 \\
3. & Dilated common bile duct & 1 \\
4. & Common bile duct adherent to gallbladder & 1 \\
5. & Gangrenous, friable gallbladder & 1 \\
\hline
\end{tabular}


The conversion rate in our study was $2.6 \%$ (14 of 526), which compares well with the incidence reported in the literature, which varies from $2 \%$ to $15 \%[7,14,15]$. There is no significant difference in the age or the sex distribution in either group of patients.

The LFTs of the patients of both the group are comparable with each other. Among the parameters studied there was no statistical difference between the total bilirubin and direct bilirubin values. However, there was a significant statistical difference in the alkaline phosphatase values, the reasons for which is not clear.

The ultrasound findings of both the groups are well matched and show no significant difference among the parameters that were looked into in the present study. However, it was observed that there were lacunae in the completeness of ultrasound reports.

The most common reason for intraoperative need for conversion to open surgery was difficulty in delineating the anatomy at the Calot's triangle.

There were no reports of cases converted due to complications such as intraoperative haemorrhage or injury to adjoining viscera. In our study, we had no difficulty in creation of pneumoperitoneum. Situations where difficulty in gallbladder extraction or instrument failure necessitated conversion did not arise. There were no deaths reported.

One bile duct injury was detected postoperatively and was treated conservatively; there was no follow-up, as the patient was transferred to another hospital on request.

In our study, which is one of the largest series from south India, we were able to identify the lacunae in completeness of ultrasound reporting. Our study is a stepping stone in initiating prospective studies on the predictive factors in conversion.

The limitation of our study was the small number of patients who had to undergo conversion. In our study, we have not quantified the thickness of the gallbladder wall and the ultrasound data available were incomplete. Many other parameters such as obesity; diabetes mellitus; body mass index; duration of symptoms; total leucocyte count; acute cholecystitis; history of biliary disease such as jaundice, cholangitis, etc.; history of pancreatitis and preoperative ERCP, which have been studied in other studies could not be included in this study because of retrospective nature of data collection. A formal scoring for difficulty of laparoscopic cholecystectomy was not done because the thrust of this article was to look at the preoperative factors for conversion.

\section{Conclusions}

The preoperative laboratory and ultrasound findings in both the groups of patients, i.e., those who underwent laparoscopic cholecystectomy and those who had to undergo conversion to open cholecystectomy, were not significantly different except for alkaline phosphatase levels. Hence, it is difficult to preoperatively predict the factors responsible for conversion. The most common intraoperative cause for conversion was difficulty in delineating the Calot's triangle.

\section{References}

1. Soper NJ, Stockmann PT, Dunnegan DL, Ashley SW (1992) Laparoscopic cholecystectomy. The new 'gold standard'? Arch Surg 127:917-921

2. Cuschieri A, Dubois F, Mouiel J, Mouret P, Becker H, Buess G et al (1991) The European experience with laparoscopic cholecystectomy. Am J Surg 161:385-387

3. Southern Surgeons Club (1991) A prospective analysis of 1518 laparoscopic cholecystectomies. N Engl J Med 324:1073-1078

4. Kane RL, Lurie N, Borbas C, Morris N, Flood S, McLaughlin B et al (1995) The outcomes of elective laparoscopic and open cholecystectomies. J Am Coll Surg 180:136-145

5. Eldar S, Sabo E, Nash E, Abrahamson J, Matter I (1997) Laparoscopic cholecystectomy for acute cholecystitis: prospective trial. World J Surg 21:540-545

6. Eldar S, Sabo E, Nash E, Abrahamson J, Mater I (1998) Laparoscopic cholecystectomy for various types of gallbladder inflammation: a prospective trial. Surg Laparosc Endosc 8:200-207

7. Livingston EH, Rege RV (2004) A nationwide study of conversion from laparoscopic to open cholecystectomy. Am J Surg 188:205-211

8. Williams LF Jr, Chapman WC, Bonau RA, McGee EC Jr, Boyd RW, Jacobs JK (1993) Comparison of laparoscopic cholecystectomy with open cholecystectomy in a single center. Am J Surg 165:459-465

9. Fried GM, Barkun JS, Sigman HH, Lawrence J, Clas D, Garzon J et al (1994) Factors determining conversion to laparotomy in patients undergoing laparoscopic cholecystectomy. Am J Surg 167:35-41

10. Lim K-R, Ibrahim S, Tan N-C, Lim S-H, Tay K-H (2007) Risk Factors for conversion to open surgery in patients with acute cholecystitis undergoing interval laparoscopic cholecystectomy. Ann Acad Med Singapore 36:631-635

11. Krahenbuhl L, Sclabas G, Wente MN, Schafer M, Schlumpf R, Buchler MW (2001) Incidence, risk factors, and prevention of biliary tract injuries during laparoscopic cholecystectomy in Switzerland. World J Surg 25:1325-1330

12. Merriam LT, Kanaan SA, Dawes LG, Angelos P, Prystowsky JB, Rege RV et al (1999) Gangrenous cholecystitis: analysis of risk factors and experience with laparoscopic cholecystectomy. Surgery 126:680-686

13. Kumar A, Thombare MM, Sikora SS, Saxena R, Kapoor VK, Kaushik SP (1996) Morbidity and mortality of laparoscopic cholecystectomy in an institutional setup. J Laparoendosc Surg 6:393-397

14. Kama NA, Kologlu M, Doganay M, Reis E, Atli M, Dolapei M (2001) A risk score for conversion from laparoscopic to open cholecystectomy. Am J Surg 181:520-525

15. Rosen M, Brody F, Ponsky J (2002) Predictive factors for conversion of laparoscopic cholecystectomy. Am J Surg $184: 254-258$ 